\title{
Optimized Design of Earthing Network for Radio Base Station
}

\author{
Jike Liu ${ }^{1, \mathrm{a}}$, Yongshuang Lin ${ }^{2, \mathrm{~b}}$, Qiang Chen ${ }^{1, \mathrm{c}}$, Zheng Qi ${ }^{1, \mathrm{~d}}$, Zhigang Wang ${ }^{1, \mathrm{e}}$ \\ ${ }^{1}$ China Information Technology Designing \& Consulting Institute Co., Ltd. \\ Zhengzhou, China \\ ${ }^{2}$ China Guangdong Mobile Communication Co., Ltd. \\ Guangzhou, China \\ Email: ${ }^{a}$ liujike@dimpt.com, b13902880005@139.com, chqg007@dimpt.com, \\ dizheng@dimpt.com, ewangzg06@dimpt.com
}

\begin{abstract}
Generally the Radio Base Station(RBS) designs include three cases: (1) The equipment room is separated with the iron tower; (2) The equipment room is enclosed by the four feet of the iron tower; and (3) The iron tower is erected on the top of equipment room. With respect to the above cases, a rational design of earthing system for various types of RBSs is an important issue concerned in the earthing project. Generally the standard earthing resistance of the mobile site should be less than $5 \Omega$ both at home and abroad, but the diversity of geographical environments where the RBS is located hinders the realization of the objective specified in the clauses. At the same time, a large number of technical personnel report that it is difficult to design the earthing system based on the standard and to realize the earthing resistance required in the clause. Certainly, it is impractical to address all issues using only one mode due to the diversity of earthing networks of RBS. Therefore, a rational earthing system design is necessitated to meet the standard earthing resistance requirement due to the difference in environmental factors between outskirts/mountainous areas and cities, equipment rooms and leased buildings. Based on a large number of research and application in $\mathbf{1 0}$ years, this article present a new theory and technology for the design of RBS's earthing network that using available area for the bleeding of lightening current instead of the requirement of earthing resistance, which has been written into the mandatory standards in china and changed the long-term innate perception of seeking lower earthing resistance. This new theory and technology makes the construction of RBS's earthing network more simple and effective.
\end{abstract}

Keywords—RBS, earthing, optimized, design

\section{PURPOSE OF EARTHING FOR RBSS}

Currently the earthing networks in use in outskirts or mountainous areas are diversified with earthing resistance ranging from several ohms to dozens of ohms, contingent upon the soil texture, earth resistivity and geographical environment where RBS is located. For the RBS currently in service, facts have proved that the earthing resistance does not have any impact on the technical parameters and signal transmission of the RBS. Theoretically speaking, the smaller the earthing resistance, the better. This is because the lightning current that flows on the earthing device will increase the earth potential at the earthing point, resulting in over-high contact voltage and step voltage. Therefore, the design of the earthing network should minimize the earthing resistance as far as possible.

According to the IEC60950 Safety Specifications of Information Technology Equipment, the communication equipment using the AC/DC converter falls into the category of equipment of basic insulation. The exposed conductive parts of such a type of equipment must be reliably earthed to prevent the voltage from damaging the human body in the event of equipment failure.

In view of the impact on the earth loop current, the analog communication equipment primarily adopting the detachable components must be earthed independently. But for the digital communication equipment primarily adopting the Large-Scale Integrated circuit (LSI), the working earth ground may and must be combined with the protection ground due to the poor anti-surge capability of the internal components though the equipment features strong antiinterference capability.

For DC system (-48V is the DC positive ground, and + 24V DC negative ground), the earthing should be targeted on at least the following two purposes:

a. Security. To prevent the hazardous voltage from striking the human body in the event of power system failure.

b. Equipment protection. To prevent the hazardous voltage from damaging the equipment in the event of power system failure.

The equipment should connect with the protection ground directly to prevent the static from damaging the equipment.

The mobile site should connect with the protection ground directly to enable discharge of lightning energy introduced in the system.

Through the above earthing purposes, it is quite obvious that the earthing resistance is based on the principle that the hazardous voltage should not be detrimental to the human body and equipment. That is, the potential fall of the faulty current cannot impose danger on the person in contact with the equipment or on the equipment itself in the case of shortcircuit of power system.

\section{COMPOSITION OF EARTHING NETWORK}

The earthing network is designed for the mobile site to obtain the lowest earthing resistance on the path of lightning current that flows to the earth, and retain the electrical potential generated into a secure range in the area it protects. 
An earthing network consisting of multiple earthing bodies can be approximately treated as an isolated panel. The capacitance of the earthing network depends on the area of the panel, and the vertical earthing body attached to the panel has a limited length $(2-3 \mathrm{~m})$, and is not enough for changing the geometrical size that is decisive to the size of capacitance. Therefore, the capacitance does not increase much, that is, the earthing resistance drops little. The earthing resistance $\mathrm{R}$ here can be expressed in the following formula:

$$
R=\frac{1}{C} \frac{\varepsilon \oint S{ }^{*}{ }^{*} d s}{1 / \rho \oint^{*}{ }^{*} d s}=\frac{\rho \varepsilon}{c}
$$

Where, $\mathrm{R}$ - The earthing resistance of the earthing body $(\Omega)$.

$\mathrm{C}$ - The capacitance $(\mathrm{F})$ of the earthing body.

$\rho-$ The earth resistivity $(\Omega . \mathrm{m})$.

$$
1
$$

$\varepsilon-\varepsilon_{\mathrm{r}} \overline{4 \pi \times 9 \times 10^{9}}$ refers to the dielectric factor of the earth $(\mathrm{F} / \mathrm{m})$.

$\varepsilon_{\mathrm{r}}-$ Relative dielectric factor of the earth.

This important formula shows that the increase of the earthing network area is crucial to the drop of earthing resistance. The capacitance may increase dramatically, that is, the earthing resistance may drop effectively, only when the length of the attached vertical earthing body is close to the equivalent radius of the earthing network and when the panel borders on a hemisphere. Even in such a case, the earthing resistance only shows a drop of $36.3 \%$, and this can be deduced from the following formula:

Suppose the earthing network is equivalent to a hemisphere with the depth of burial of 0 , radius of cross section $r$ and height of the hemisphere $R_{1}=\rho / 4 r$ : $R_{2}=\rho / 2 \pi r$

$$
\mathrm{R}_{1} / \mathrm{R}_{2}=0.637
$$

It is thus obvious that the earthing resistance is related to the area of the earthing network, and the vertical earthing body of $2-3 \mathrm{~m}$ attached to the earthing network does not help much in reducing the earthing resistance. With respect to the design of the earthing network, the idea of thickening the vertical earthing bodies to reduce the earthing resistance is unadvisable. The earthing network should be regarded as a two-dimensional panel in a macro sense. No matter how thick the vertical earthing bodies are, (compared with the equivalent radius of the earthing network, the length of the vertical earthing body should be at least one order of magnitude smaller) even if they are as thick as a solid steel sheet with the thickness of $2-3 \mathrm{~m}$, the earthing resistance does not drop much.

\section{EARTHING INSTALLATION OF RBS}

The earthing device of the mobile site generally consists of the earthing network, as shown in the figure 1:

The joint ground consisting of horizontal ring earthing body is used as a means for the public earthing network to lower the earth potential difference between earthing body subsystems in the case of lightning. This method helps balance the earth potential of the mobile site and enhances the capability of dissipating lightning current.



Figure 1 Composition of earthing network

\section{RELATION BEtweEn AREA AND EARTHING RESISTANCE}

The earthing resistance of the joint earthing body (primarily composed of horizontal earthing body, with edges closed):

$$
\mathrm{R}=0.44 \frac{\rho}{\sqrt{A}}+0.159 \frac{\rho}{L} \operatorname{Ln} \frac{8 \mathrm{~A}}{h d \times 10^{4}}
$$
2).

where, $\mathrm{A} \longrightarrow$ The area of the earthing network (Unit: $\mathrm{m}$

L_ Length of the earthing body: Total length of the vertical and horizontal earthing bodies (Unit: $\mathrm{m}$ ).

$\mathrm{D}$-Diameter of the horizontal earthing body (Unit: $\mathrm{m}$ ).

$\mathrm{H}-$ Depth of burial of the horizontal earthing body (Unit: m).

$\rho$ Earth resistivity (Unit: $\Omega \cdot \mathrm{m}$ ).

From the above formula, it is quite obvious that the earthing resistance is mainly contingent upon the area of the earthing network. While the last item in the formula reveals that the burial depth, the diameter of the earthing body, and total length of horizontal and vertical earthing bodies in the network work little, and generally contribute $8 \%$ of $\mathrm{R}$, in reducing the earthing resistance. According to the calculation of the industrial frequency earthing resistance of joint earthing network, the $\mathrm{R}$ in the above formula is about:

$$
\mathrm{R}=\frac{\sqrt{\pi}}{4} \square \frac{P}{\sqrt{A}}+\frac{P}{L}=0.443 \frac{P}{\sqrt{A}}+\frac{P}{L} \approx 0.5 \frac{P}{\sqrt{A}}
$$

It is revealed in $\mathrm{R}=0.5 \rho / \sqrt{S}$ that, to reduce the earthing resistance under the condition of the same earth resistivity, you have to increase the area of the earthing network. Table A-1 lists the areas of earthing networks when the earthing resistance $\mathrm{R}$ keeps at $5 \Omega$ in the case of different earth resistivities. 
TABLE I RELATION BETWEEN EARTH RESISTIVITY AND AREA OF EARTHING NETWORK SIZE WHEN R KEEPS AT $5 \Omega$

\begin{tabular}{l|l|l|l|l|l|l}
\hline \multicolumn{7}{|c}{ In case $\mathrm{R}=0.5 \rho / \sqrt{S}=5 \Omega$} \\
\hline$\rho(\Omega \cdot m) \rho(\Omega . \mathrm{m}$. & $\begin{array}{l}10 \\
0\end{array}$ & $\begin{array}{l}20 \\
0\end{array}$ & 400 & 800 & 1000 & 1600 \\
\hline $\mathrm{S}\left(\mathrm{m}^{2}\right)$ & $\begin{array}{l}10 \\
0\end{array}$ & $\begin{array}{l}40 \\
0\end{array}$ & $\begin{array}{l}160 \\
0\end{array}$ & $\begin{array}{l}640 \\
0\end{array}$ & $\begin{array}{l}1000 \\
0\end{array}$ & $\begin{array}{l}2560 \\
0\end{array}$ \\
\hline
\end{tabular}

This shows that it is hard to maintain the earthing resistance of the earthing network at $5 \Omega$ in the mountainous areas with high earth resistivity.

\section{EARTHING NETWORK AND IMPULSE}

\section{RADIUS/OPTIMAL AREA OF EARTHING NETWORK}

For the mobile site located on the mountain, it is impractical to realize small earthing resistance (for example, $5 \Omega$ ) within a limited area. But we may enable the potential in every parts of the mobile site to rise accordingly and balance the impulse voltage between devices in the office to strengthen discharge of lightning current in the event of lighting stroke by way of equalizing earth potential, adopting joint ground and improving the layout of earthing cable. This raises the strict restriction over the earthing resistance of the mobile site, and at the same time involves the trade-off between the safety effect of the ground potential and the expense necessary to achieve a very low resistance.

\section{A. Earthing network and impulse radius}

The resistance, generated when the earthing body of one lightning rod is in contact with the lightning, significantly differs from the earthing resistance of the DC and power frequency current. The physical process induced by the lightning in the soil also differs quite a lot from that generated by the power frequency current. The major difference between them lies in the formation of lightning and the characteristic of the soil to transmit the high frequency electromagnetic wave. The lightning stroke is characteristic of the shock wave with tremendously high current. When the electric field intensity around the earthing body exceeds the breakdown strength of the soil because of the large amplitude of the lightning current, the arc is generated, achieving the effect of expanding the area of the earthing network actually. Therefore, the earthing resistance of the earthing network drops by the agency of the lightning current.

The lightning current exhibits the following characteristics when dissipating energy to the soil through the earthing body:

The lightning current produces a strong electrical field around the earthing body due to large current amplitude when flowing to the soil through the earthing device. And the soil resistivity is also affected by the electrical field intensity. With the increase of the electrical field intensity, that is, with the increase of current density, the soil resistivity drops.

The lightning current is equal to the high frequency power supply. In addition to the resistance and conductance, the inductance and capacitance of the earthing body also have an impact on the impulse impedance. The impact degree is dependent upon the shape of the earthing body, waveform and amplitude of the impulse current, and dielectric factor $\varepsilon r$ and earth resistivity $\rho$.

Unlike the DC and power frequency current, the impulse current does not penetrate deep earth stratum and only flows in the shallow soil due to the skin effect of the high frequency current.

When the electrical field intensity around the earth body reaches certain value after the lightning current flows to the soil through the earthing device, the voltage is non-linear with the current.

Therefore, when the impulse current or lightning current dissipates energy to the earth through the earthing body, the impulse earthing resistance rather than the power frequency earthing resistance is used to measure the effect of impulse earthing. The impulse earthing resistance is the proportion of the impulse voltage amplitude of earthing device to the impulse current. The above definition shows that the impulse earthing resistance carries no physical meaning because the impulse voltage amplitude and current amplitude does not occur simultaneously (by the agency of the inductance of the earthing body, the former occurs prior to the latter). But this definition can be used to figure out the impulse voltage amplitude when the impulse current is dissipated through the earthing body if the impulse current amplitude and impulse resistance are known.

The surface of the earthing body can be approximately regarded as equipotential surface in the case of power frequency no matter how large the area of an earthing network is, so the total area of the earthing network can be made full use of. A lot of earthing bodies constitute a mesh earthing body in the earth ground. The impulse equivalent radius of the earthing network is a constant by the agency of the impulse current when the earth resistivity and dielectric factor are definite. The impulse equivalent radius, however, is much smaller than the equivalent radius of the earthing network at power frequency, that is, only a small area of the earthing network is made use of in the presence of impulse current. The earthing bodies, however, are made full use of in the case of power frequency because all earthing bodies contribute to the current dissipation due to the equal potential in the earthing network. This explains why the earthing resistance is in reverse proportion to the square root of the earthing network area. This case is different when the earthing body is in contact with the lightning current. The potential of the earthing network is not equal by the agency of the inductance of the earthing body, and the farther away from the point where the lightning current is introduced, the lower (even 0) the potential on the earthing body. The potential decreases based on exponential curve. Only the earthing network around the point where the lightning current is introduced plays a part in dissipating energy, and moreover, the energy dissipation is in proportion to the potential distribution in this area.

\section{B. Optimal area of earthing network}

The proportion of impulse equivalent radius to the equivalent radius of the earthing network: 


$$
\mathrm{K}=\frac{r_{c h}}{r}=\frac{\rho \sqrt{\varepsilon r}}{60 \sqrt{\pi A}}\left(1-e \frac{-60 \sqrt{\pi A}}{\rho \sqrt{\pi r}}\right)
$$

Where,

$$
\begin{aligned}
& \mathrm{r}_{\mathrm{ch}} \text { - Impulse equivalent radius }(\mathrm{m}) \\
& \mathrm{r}-\text { Equivalent radius }(\mathrm{m}) \text { of the earthing network } \\
& \rho-\text { Area of earthing network }\left(\mathrm{m}^{2}\right) \\
& \mathrm{er}-\text { Earth resistivity }(\Omega \cdot m)
\end{aligned}
$$

\begin{tabular}{|c|c|c|c|c|}
\hline 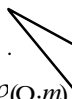 & $A=100$ & $A=400$ & $A=1600$ & $\mathrm{~A}=6400$ \\
\hline 250 & $53.44 \%$ & $33.19 \%$ & $17.57 \%$ & $8.82 \%$ \\
\hline 500 & $71.63 \%$ & $53.44 \%$ & $33.19 \%$ & $17.57 \%$ \\
\hline 1000 & $84.19 \%$ & $71.63 \%$ & $53.44 \%$ & $33.19 \%$ \\
\hline 2000 & $91.6 \%$ & $84.19 \%$ & $71.63 \%$ & 53.44 \\
\hline
\end{tabular}

TABLE II UTILIZATION OF IMPULSE RADIUS AND EQUIVALENT RADIUS OF EARTHING NETWORK IN THE CASE OF DIFFERENT EARTH RESISTIVITIES

The proportion of impulse radius to the equivalent radius of earthing network can be taken into account for the optimized design of earthing network under the conditions of different earth resistivities and areas of earthing networks. Table 2 lists the rule that the impulse equivalent radius and equivalent radius of earthing network change when the earth resistivity $\rho=250-2000 \Omega$.m, and area of earthing network $\mathrm{A}=100-6400 \mathrm{~m}^{2}$. We can draw a conclusion from the above rule that the area of the earthing network should be controlled within $(20 \mathrm{~m})^{2}=400 \mathrm{~m}^{2}$ for the optimized design of the earthing network based on the geographical environment where the base station is located. In this case, the utilization of the impulse equivalent radius is quite high for the earthing network in the soil with high resistivity (the utilization is up to $84.19 \%$ when the earth resistivity is $2000 \Omega . m$ ). When the earth resistivity is less than $500 \Omega . \mathrm{m}$, the area of the earthing network can be less than $400 \mathrm{~m}^{2}$. On such a basis, the utilization of the earthing network can be much higher after the application of horizontal earthing bodies. In addition, in view of the capability of the vertical earthing bodies to enhance the discharge of lightning current, a circuit of vertical earthing bodies can be added at the impulse equivalent radius, with the equivalent radius centering on the iron tower. The use of vertical earthing bodies is to expedite the discharge of lightning current instead of lowering the earthing resistance of the earthing network.
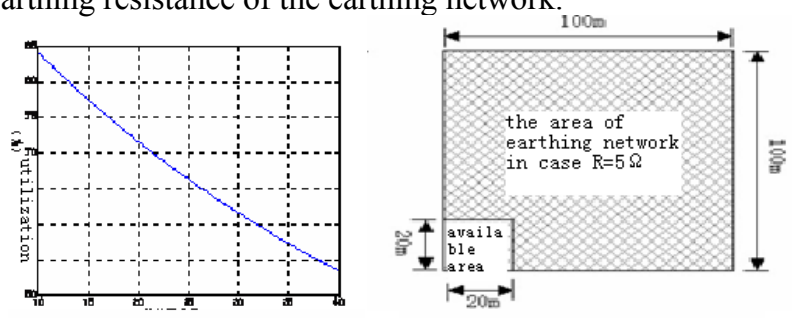

Figure 2 Relation between Figure 3 comparison between utilization and radius. optimized utilization area and $\mathrm{R}=5 \Omega$
The relationship between the utilization ratio and the radius (m)of the earthing network in case of $\rho=1000 \Omega \cdot m$ is shown in figure 2 . When radius of the earthing network is $10 \mathrm{~m}$, the utilization ratio is $85 \%$. The utilization ratio drops rapidly along with the increase of the radius. The area of earthing network requires $10000 \mathrm{~m}^{2}$ in order to fulfil the requirement of $\mathrm{R}=5 \Omega$. But according the theory of available area for the bleeding of lightening current, the area is $400 \mathrm{~m}^{2}$ which is $4 \%$ of before, which is shown in figure 3 .

Using the theory of available area for the bleeding of lightening current instead of the requirement of earthing resistance, changes the long-term innate perception of seeking lower earthing resistance, which is more rational. This subversive discovery is a very important guideline for construction of RBS and has been written into the mandatory standards (YD5098、GB50689、YD2324) in china. According the application on millions of RBS in 7 years, the new technology is not only very reliable and effective, but also saving much expense. The expense of earthing network of a RBS was 35,000 RMB averagely, sometimes above $100,000 \mathrm{RMB}$. The expense has been dropped at 5,000 RMB now, which saves $80 \%$ expense average station.

\section{CONCLUSIONS}

When RBS adopts the joint ground, it can be specified that only one earthing resistance is set up in order to reduce the investment in construction of earthing network in the case of low earth resistivity. But in areas with high earth resistivity, the area of the earthing network can be used to judge whether the earthing resistance satisfies the earthing requirement in the event of lightning strokes. In addition, the zinc-coated flat sheet of $20-30 \mathrm{~m}$ should be laid at four corners of the earthing network as radiated earthing to provide better channels for dissipation of lightning current.

\section{REFERENCES}

[1] Liu Jike, Wangzhigang, Qizheng, "Study on Lightning Protecting of Distributed Base Station and Applications", 2012 Asia-Pacific Symposium \& Exhibition on Electromagnetic Compatibility.

[2] Liu Jike, "Comprehensive Communication Building Lightning Protection and Grounding", Telecommunications Science, March 1995.

[3] Liu Jike, Limeng, Chenqiang, "ITU-T K.56 Lightning Protecting of Radio Base Station", 2007. 